\title{
Comparison of Uniform and Non-uniform Pressure Approaches Used to Analyze an Adsorption Process in a Closed Type Adsorbent Bed
}

\author{
Gamze Gediz Ilis · Moghtada Mobedi · Semra Ülkü
}

Received: 8 June 2012 / Accepted: 29 January 2013 / Published online: 13 February 2013

C) Springer Science+Business Media Dordrecht 2013

\begin{abstract}
Heat and mass transfer in an annular adsorbent bed filled with silica gel particles is numerically analyzed by uniform and non-uniform pressure approaches. The study is performed for silica gel-water pair, particle radius from 0.025 to $1 \mathrm{~mm}$ and two bed radii of 10 and $40 \mathrm{~mm}$. For uniform pressure approach, the energy equation for the bed and the mass transfer equation for the particle are solved. For non-uniform pressure approach, the continuity and Darcy equations due to the motion of water vapor in the bed are added, and four coupled partial differential equations are solved. The changes of the adsorbate concentration, pressure, and temperature in the bed throughout the adsorption process for both approaches are obtained and compared. The obtained results showed that the particle size plays an important role on the validity of uniform pressure approach. Due to the interparticle mass transfer resistance, there is a considerable difference between the results of the uniform pressure and non-uniform pressure approaches for the beds with small size of particles such as $r_{\mathrm{p}}=0.025 \mathrm{~mm}$.
\end{abstract}

Keywords Heat and mass transfer - Inter and intraparticle mass transfer resistance . Adsorbent bed

\section{List of symbols}

\section{Variables}

$C_{\mathrm{p}} \quad$ Specific heat of adsorbent $\left(\mathrm{Jkg}^{-1} \mathrm{~K}^{-1}\right)$

$D_{\text {eff }} \quad$ Effective mass transfer diffusivity $\left(\mathrm{m}^{2} \mathrm{~s}^{-1}\right)$

G. G. Ilis · M. Mobedi ( $\bowtie)$

Mechanical Engineering Department, Izmir Institute of Technology, Urla, 35430 Izmir, Turkey e-mail: moghtadamobedi@ iyte.edu.tr

S. Ülkü

Chemical Engineering Department, Izmir Institute of Technology, Urla, 35430 Izmir, Turkey 


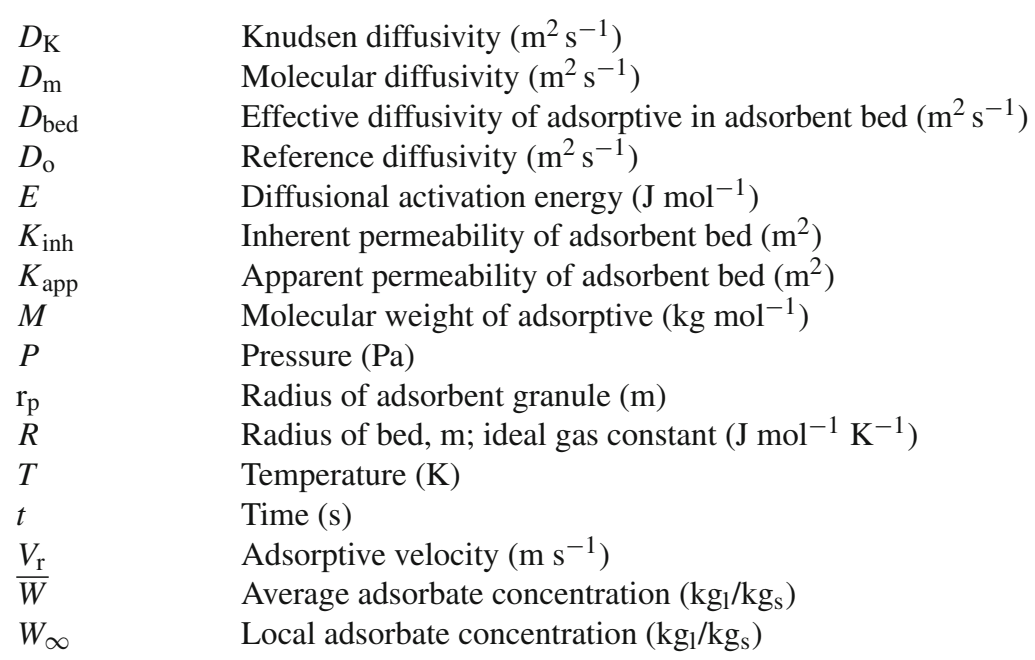

\section{Greek symbols}

$\begin{array}{ll}\rho & \text { Density }\left(\mathrm{kg} \mathrm{m}^{-3}\right) \\ \Delta H_{\mathrm{ads}} & \text { Heat of adsorption }\left(\mathrm{J} \mathrm{kg}^{-1}\right) \\ \varphi & \text { Porosity } \\ \phi & \text { A dependent variable } \\ \lambda_{\text {eff }} & \text { Effective thermal conductivity }\left(\mathrm{W} \mathrm{m}^{-1} \mathrm{~K}^{-1}\right) \\ \mu & \text { Adsorptive viscosity }\left(\mathrm{Ns} \mathrm{m}^{-2}\right) \\ \sigma & \text { Collision diameter for Lennard-Jones potential }\left(\mathrm{A}^{0}\right) \\ \Omega & \text { Collision integral } \\ \tau & \text { Tortuosity }\end{array}$

\section{Subscripts}

$\begin{array}{ll}\mathrm{a}, \mathrm{d} & \text { Final and initial conditions of adsorption } \\ \mathrm{i} & \text { Inner } \\ \mathrm{l} & \text { Adsorptive } \\ \mathrm{o} & \text { Outer } \\ \mathrm{s} & \text { Adsorbent } \\ \mathrm{sat} & \text { Saturation } \\ \mathrm{v} & \text { Adsorbate } \\ \infty & \text { Equilibrium }\end{array}$

\section{Introduction}

Adsorption technology has wide applications in pollution control, gas separation, drying process, catalytic reaction, and water and air purification. A new application of adsorption technology in recent years is adsorption-based heat storage and refrigeration systems. Several theoretical and numerical studies have been performed on the development of the adsorption heat pump due to its advantages such as operation with low temperature heat reservoirs, 
utilization of waste heat or alternative thermal energy sources. The use of the adsorptiondesorption cycle was first proposed by Close and Dunkle (1977), who obtained warm and relatively dry air using a silica gel adsorbent bed. After that a solar refrigerator was constructed by Tchernev $(1976,1980)$. A review on the reported studies, advantages and disadvantages of adsorption heat pump are given in Demir et al. (2008).

In an adsorption process, the solid and the fluid adsorbed on the solid surface are referred as adsorbent (e.g., silica gel) and adsorbate (e.g., adsorbed water), respectively. The adsorbable substance which is in the vapor phase and exists in the voids between particles is called as adsorptive (e.g., water vapor). Adsorptive tends to be diffused into the pores of the adsorbent. Adsorbent bed, in which adsorption and desorption processes occur, is the crucial component of an adsorption heat pump. The adsorbent bed used in an adsorption heat pump is a closed type operating under a low or high pressure. It enables combination of heat storage and heat pumping functions in the same system. Although studies on coating type adsorbent bed continues (e.g.,Marletta et al. 2002; Restuccia et al. 2004), granular-type adsorbent bed is still used in many investigations (e.g.,Demir et al. 2009; Ilis et al. 2011). Two types of mass transfer occur in a closed type granular adsorbent bed as mass transfer within the adsorbent particle (intraparticle mass transfer) and mass transfer in the voids between adsorbent particles (interparticle mass transfer). The intraparticle mass transfer is formed generally by diffusion mode of transport in the adsorbent particle. Hence, the solid diffusion or linear drive force (LDF) model is used to determine the change of adsorbate concentration in the adsorbent particle with time. The interparticle mass transfer mostly occurs due to the gradient of adsorptive concentration (i.e, pressure) in the adsorbent bed and it can be described by Darcy Law. Two approaches, uniform and non-uniform pressure approaches, can be used for the simulation of heat and mass transfer in a closed adsorbent bed. In the uniform pressure approach, the interparticle mass transfer resistance is neglected; however, it is taken into account in non-uniform pressure approach.

Table 1 shows the list of some studies on heat and mass transfer in an adsorbent bed of adsorption heat pump. The employed approach (uniform or non-uniform pressure approach), the coordinate system, bed porosity, bed thickness, and isotherm model are also presented in the table. As can be seen from Table 1, both the uniform pressure approach (Ilis et al. 2010, 2011; Chua et al. 2004; Wang and Chua 2007; Saha et al. 2009; Chahbani et al. 2002; Leong and Liu 2004a) and non-uniform pressure approach (Marletta et al. 2002; Demir et al. 2009; Leong and Liu 2004a,b, 2006, 2008; Liu and Leong 2005; Sun et al. 1995; Ben Amar et al. 1996; Restruccia et al. 2002; Maggio et al. 2009; Li Yong and Sumathy 2004) were preferred by many researchers to simulate heat and mass transfer in an adsorbent bed. Radial adsorbent bed was considered in the most of the studies except the study of Sun et al. (1995) in which a rectangular bed was analyzed. Most of the researchers performed one-dimensional study, and the changes of temperature and adsorbate concentration with time were obtained only in radial direction. The two-dimensional studies were performed by Saha et al. (2009); Ben Amar et al. (1996); Marletta et al. (2002); Maggio et al. (2009), and Ilis et al. (2011). A wide range of adsorbent bed thickness was analyzed. The analyzed bed thickness varies between 3 and $130 \mathrm{~mm}$. The minimum bed thickness with $3 \mathrm{~mm}$ was considered in the study of Maggio et al. (2009), while the maximum bed thickness with 130 was analyzed by Demir et al. (2009) for the direct use of adsorption heat pump in industrial chimneys. The adsorbent bed porosity was around 0.38 in most of the studies. The smallest particle radius was $0.01 \mathrm{~mm}$ and the largest one was $1.6 \mathrm{~mm}$ in the studies of Sun et al. (1995) and Demir et al. (2009), respectively. Furthermore, the isotherm model is also presented in Table 1. The isotherm model is based on the adsorbent-adsorbate pair. 


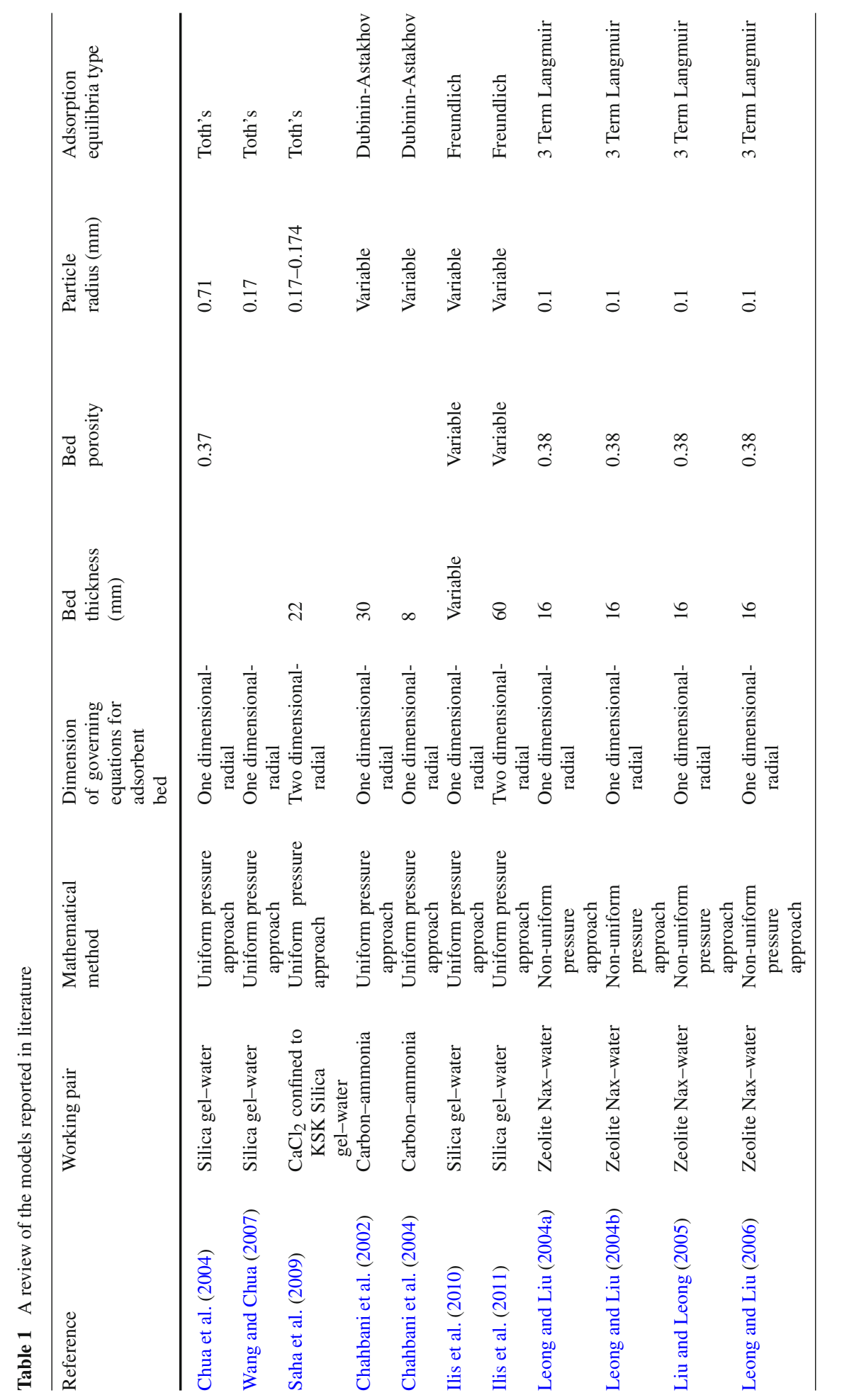




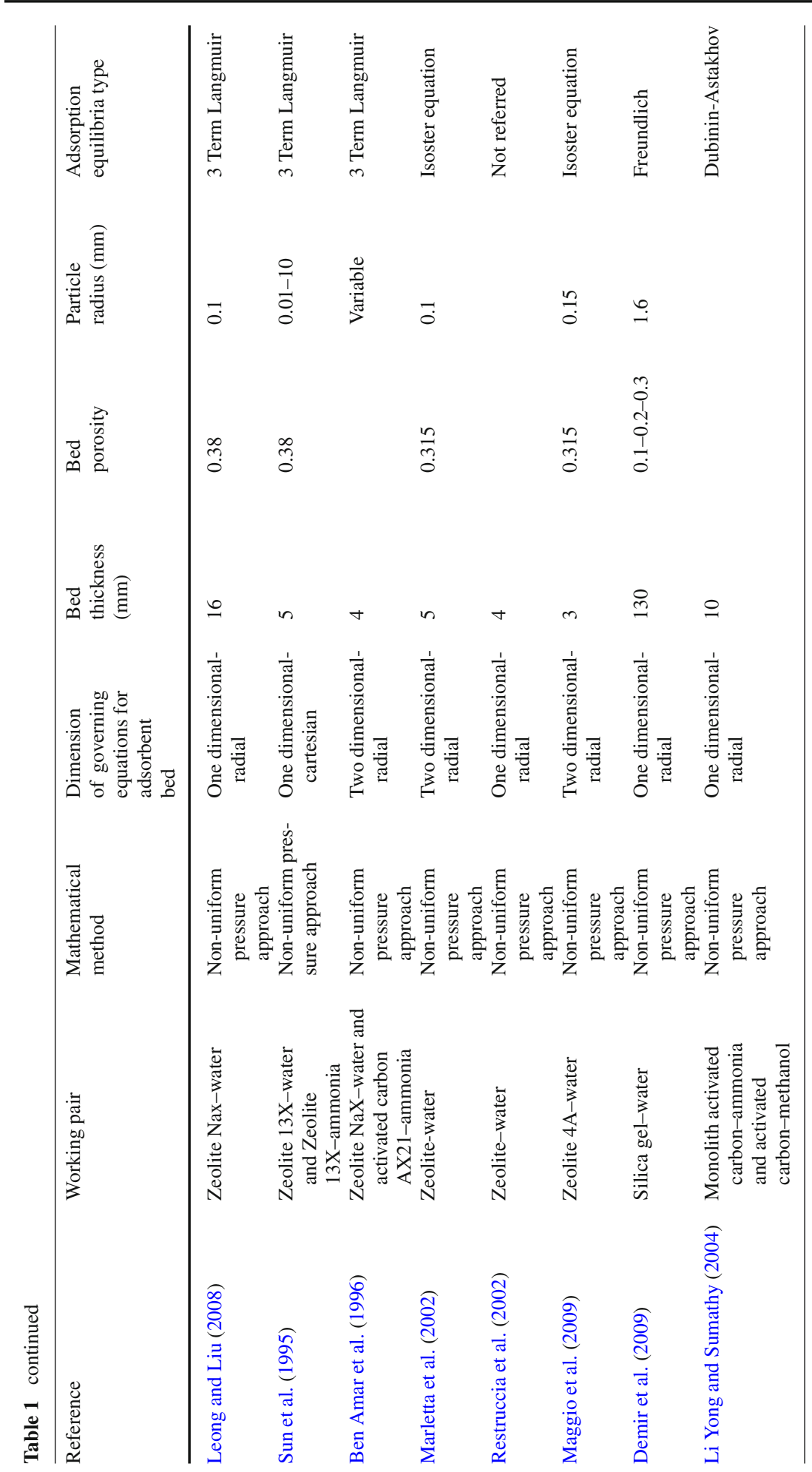


The importance of analyzing heat and mass transfer in an adsorption process is not limited to the adsorption heat pump. Several studies on heat and mass transfer in packed bed and rotary-type desiccant wheels can be found in literature. For instance, Golubovic and Worek (2004) studied the pressure effect on sorption process in the rotary desiccant wheels and a mathematical model for a case with condensation inside the channels of a desiccant wheel was derived. Sphaier and Worek (2008) proposed a novel solution scheme for a periodic heat and mass transfer in a regenerator. They studied the solution approach involving two-dimensional formulations that accounts locally for the diffusion in a sorbent medium. Al-Sharqawi and Lior (2004) performed a study on heat and mass transport for laminar and turbulent humid air flows over desiccant plates. The continuity, momentum, energy, and mass transfer equations are solved for air and water vapor flow. The energy and solid mass diffusion equations were solved for adsorbent region. Further studies on heat and mass transfer in the adsorbents bed or adsorbent layer can be found in literature (Ruivo et al. 2006, 2008; Hajji and Lavan 2007).

The aim of the present study is to analyze heat and mass transfer in a granular cylindrical adsorbent bed using uniform and non-uniform pressure approaches and compare the obtained results. The study is performed only for the adsorption process. The adsorbent particle is spherical and its radius is changed from 0.025 to $1 \mathrm{~mm}$ to find out the effect of particle size on the use of uniform pressure approach for simulation of heat and mass transfer in the bed. The effect of particle size on the adsorption period is also studied to determine a minimum adsorption period for an adsorption process. The change of local and average adsorbate concentration, pressure, and temperature with time are calculated and plotted.

The present study shows that the validation of the uniform pressure approach for the studied bed should be taken into account before its application. The uniform pressure approach may yield extremely wrong results if the interparticle mass transfer resistance exits. The study also shows that how the results between the uniform and non-uniform pressure approaches become closer to each other by the increase of the void size between particles. It is also indicated that the interparticle mass transfer depends on either the particle size (or void size between particle) and thickness of the bed. There is an optimum particle size for minimum adsorption period. To our best of knowledge, the present problem has not been studied before in the aforementioned manner, therefore the obtained results are new and original.

\section{The Considered Adsorbent Bed}

Figure 1 shows the schematic view of the analyzed annulus adsorbent bed filled with the adsorbent particles. The radius of adsorbent particle is changed from 0.025 to $1 \mathrm{~mm}$. The adsorbent bed has a cylindrical shape. The upper and bottom surfaces of the adsorbent bed are insulated and the transfer of heat and mass occurs only in radial direction. The thermal resistance of the metal casing is neglected. The adsorptive can flow from inner surface, $R=\mathrm{R}_{i}$, toward the outer surface, $R=\mathrm{R}_{o}$. The study is performed for silica gel-water pair and for two adsorbent beds with thickness of 10 and $40 \mathrm{~mm}$. The inner radius of both adsorbent beds is $\mathrm{R}_{i}=10 \mathrm{~mm}$. Two locations at $R=16.7$ and $43.3 \mathrm{~mm}$ for the bed thickness of $40 \mathrm{~mm}$ and two locations at $R=11.7$ and $18.3 \mathrm{~mm}$ for the bed thickness of $10 \mathrm{~mm}$ can also be seen from Fig. 2. The changes of temperature, concentration, and pressure with time for these locations are obtained and drawn against time. The porosity of the adsorbent bed is assumed as 0.35 . The thermophysical properties of the considered silica gel-water pair are given in Table 2. 


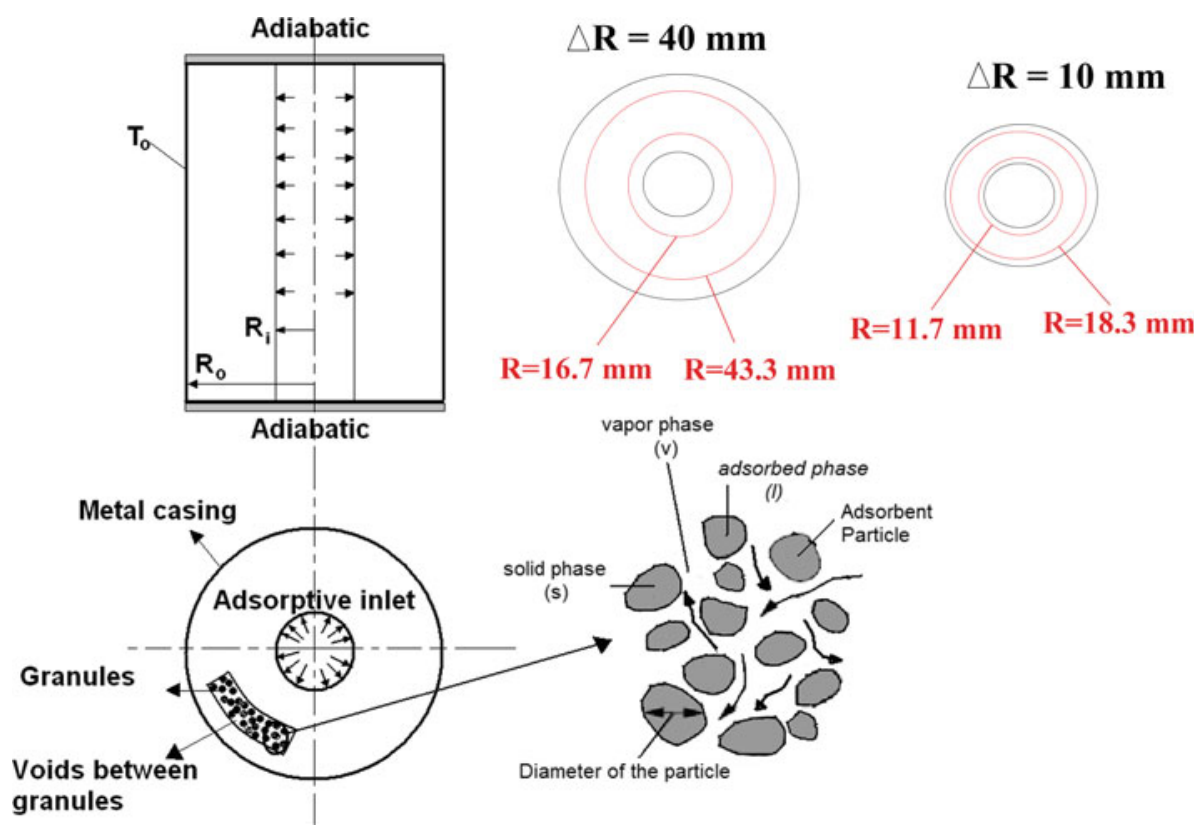

Fig. 1 The schematic view of analyzed annular adsorbent bed filled with the adsorbent granules
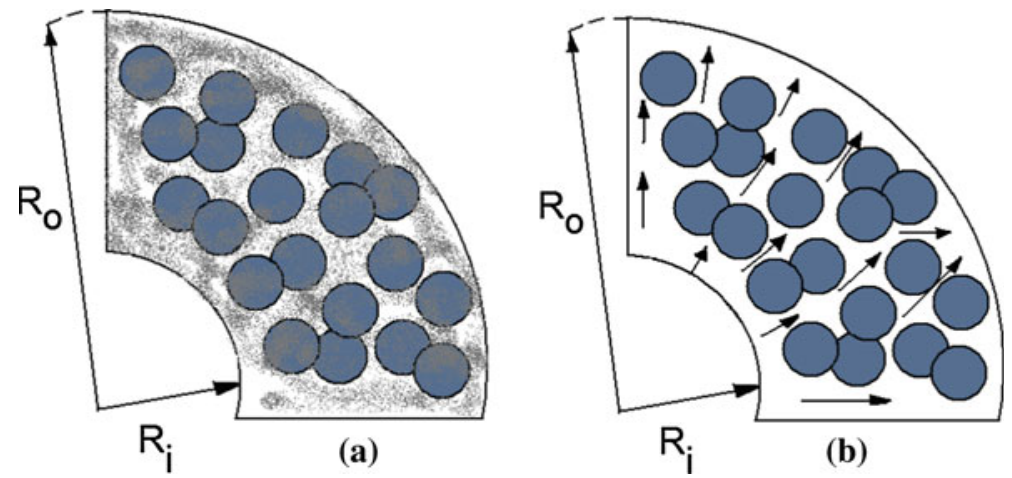

Fig. 2 A section of adsorbent bed, a uniform pressure approach, b non-uniform pressure approach

\section{Governing Equations}

As it was mentioned before, two approaches are used to determine temperature and concentration in an adsorbent bed. In the uniform pressure approach, the interparticle mass transfer resistance is assumed negligible; hence the adsorptive pressure in the entire adsorbent bed is uniform as shown in Fig. 2a. The heat transfer resistance and intraparticle mass transfer resistance are parameters that control the adsorbate concentration inside the bed. Since the temperature in the bed changes both in time and space, a heat transfer equation without convective term is solved to determine local temperature throughout the adsorption process. In the non-uniform pressure approach, the interparticle mass transfer resistance is taken into account (see Fig. 2b) and the gradient of adsorptive pressure is calculated. A convective 
Table 2 Thermophysical properties of the studied silica gel-water pair at $T_{\text {mean }}=53.5^{\circ} \mathrm{C}$

Silica gel-water

\begin{tabular}{|c|c|}
\hline Density of adsorbent $(\mathrm{s})\left(\mathrm{kg} / \mathrm{m}^{3}\right)$ & 670 \\
\hline Density of adsorptive (v) $\left(\mathrm{kg} / \mathrm{m}^{3}\right)$ & 0.09838 \\
\hline Density of adsorbate $(l)\left(\mathrm{kg} / \mathrm{m}^{3}\right)$ & 986.19 \\
\hline Cp of adsorbent $(\mathrm{s})(\mathrm{kJ} / \mathrm{kg} \mathrm{K})$ & 0.88 \\
\hline Cp of adsorptive (v) (kJ/kg K) & 1.907 \\
\hline Cp of adsorbate $(l)(\mathrm{kJ} / \mathrm{kg} \mathrm{K})$ & 4.183 \\
\hline Thermal conductivity of adsorbent (s) (W/mK) & 0.198 \\
\hline Thermal conductivity of adsorptive $(\mathrm{v})(\mathrm{W} / \mathrm{mK})$ & 0.02146 \\
\hline Thermal conductivity of adsorbate $(l)(\mathrm{W} / \mathrm{mK})$ & 0.647 \\
\hline Heat of adsorption $(\mathrm{kJ} / \mathrm{kg})$ & 2369 \\
\hline Molecular weight of water $(\mathrm{kg} / \mathrm{mol}) \mathrm{M}$ & 18 \\
\hline Reference diffusivity $\left(\mathrm{m}^{2} / \mathrm{s}\right) \mathrm{D}_{\mathrm{O}}$ & $2.54 \times 10^{-4}$ \\
\hline Diffusion activation energy $\left(\mathrm{J} / \mathrm{mol}^{-1}\right)($ Bird et al. 2002) E & $4.2 \times 10^{4}$ \\
\hline Collision diameter for Lennard-Jones potential (A) (Cussler 1997) $\sigma$ & 2.641 \\
\hline Collision integral (Cussler 1997) $\Omega$ & 2.236 \\
\hline Boltzmann's constant (J/K molecule) (Incropera and DeWitt 1996) k & $1.38 \times 10^{-23}$ \\
\hline Tortuosity (Karger and Ruthven 1992) $\tau$ & 3 \\
\hline Viscosity of water vapor ( $\mathrm{kNs} / \mathrm{m}^{2}$ at $\left.300 \mathrm{~K}\right)$ (Incropera and DeWitt 1996) $\mu$ & $10.29 \times 10^{-9}$ \\
\hline
\end{tabular}

transport term appears in the heat transfer equation. Two additional equations (i.e., continuity and Darcy equations) should be solved to obtain the adsorptive velocity and concentration in the bed.

The mechanisms of heat and mass transfer in a granular adsorbent bed are coupled and complicated; hence some assumptions have to be made to pose the governing equations. The considered assumptions are; (1) the adsorbent bed consists of uniform size spherical adsorbent particles, (2) the particles arrangement is not changed and thus the bed porosity is constant for different particle sizes, (3) the adsorptive and adsorbent particle are in thermal equilibrium, (4) the thermal resistance within the adsorbent particle is neglected, (5) thermal properties of the adsorbent, adsorptive, and adsorbate are constant, (6) heat transfer at the inner radius of bed (i.e., $R=R_{\mathrm{i}}$ ) is negligible, (7) wall thermal resistance between the bed surface and particle is not considered.

The governing equations of uniform and non-uniform pressure approaches used in the analysis of the heat and mass transfer in the adsorbent bed are separately presented in the following subsections.

\subsection{Uniform Pressure Approach}

The interparticle mass transfer resistance is assumed negligible in this approach. The voids between particles are large and/or the adsorbent bed is thin; consequently the adsorptive motion is sufficiently fast to assume a uniform pressure in the entire adsorbent bed. The heat transfer equation for the adsorbent bed can be written as:

$$
\left(\rho C_{p}\right)_{\mathrm{eff}} \frac{\partial T}{\partial t}=\lambda_{\mathrm{eff}} \frac{1}{R} \frac{\partial}{\partial R}\left(R \frac{\partial T}{\partial R}\right)+(1-\varphi) \rho_{\mathrm{s}} \Delta H_{\mathrm{ads}} \frac{\partial \bar{W}}{\partial t}
$$


where $\left(\rho C_{\mathrm{p}}\right)_{\text {eff }}$ and $\lambda_{\text {eff }}$ are the effective thermal capacitance and conductivity of the adsorbent bed. The effect of water adsorption in the silica gel particle is contributed by $\partial \bar{W} / \partial t$ in Eq. (1). Since the pressure inside of the bed is assumed uniform, there is no need to write a mass transfer equation for water vapor flowing through the bed. However, an equation for determination of adsorption rate in the adsorbent particle is required. The LDF model is used to determine the change of mean adsorbate concentration in the particle with time;

$$
\frac{\partial \bar{W}}{\partial t}=\frac{15 D_{\text {eff }}}{r_{\mathrm{p}}^{2}}\left(\bar{W}_{\infty}-\bar{W}\right)
$$

where $D_{\text {eff }}$ and $r_{\mathrm{p}}$ represent the effective mass diffusivity and radius of the adsorbent particle. $D_{\text {eff }}$ can be found from Arrhenius equation (Ben Amar et al. 1996):

$$
D_{\text {eff }}=D_{\mathrm{o}} \mathrm{e}^{-E / R T}
$$

where $D_{\mathrm{o}}$ is the reference diffusivity and $E$ is the diffusion activation energy (Table 2). In order to solve mass transfer equation for the particle (Eq. (3)), a relation for equilibrium state (i.e., $\bar{W})_{\infty}$ must be known. The following isotherm equation is used to determine the adsorbate equilibrium concentration in the silica gel particle for a given pressure and temperature (Leong and Liu 2004a; Sakoda and Suzuki 1984, 1986):

$$
\bar{W}_{\infty}=k\left(P / P_{\text {sat }}(T)\right)^{1 / n}
$$

where $k$ and $n$ are the constants for the specified adsorbent-adsorbate pair. For the considered silica gel-water pair, the values of $k$ and $n$ are 0.552 and 1.6, respectively. The symbol $P_{\text {sat }}$ represents saturation pressure of water vapor at the considered temperature. The following mathematical relation was used to determine value of $P_{\text {sat }}$ based on the local temperature in the bed (San and Lin 2008):

$$
P_{\text {sat }}=0.1 \mathrm{e}^{(20.5896-5098.26 / T)}
$$

The effective thermal capacity and thermal conductivity are calculated using the following relations:

$$
\begin{gathered}
\left(\rho C_{\mathrm{p}}\right)_{\mathrm{eff}}=(1-\varphi)\left\{\left(\rho C_{\mathrm{p}}\right)_{\mathrm{s}}+\rho_{\mathrm{s}} C_{p_{1}} \bar{W}\right\}+\varphi\left(\rho C_{\mathrm{p}}\right)_{v} \\
\lambda_{\text {eff }}=(1-\varphi) \lambda_{\mathrm{s}}+\varphi \lambda_{v}
\end{gathered}
$$

Figure 3 shows an isobaric adsorption process on Clapeyron diagram. The adsorption process is started when the adsorbate concentration in the adsorbent bed is $W_{\mathrm{d}}$ and the bed temperature is at $T_{\mathrm{d}}$. The process is terminated when the adsorbate concentration attains to $W_{\mathrm{a}}$ while the bed temperature is decreased to $T_{\mathrm{a}}$. The bed outer surface temperature is at $T_{\mathrm{a}}$ during the adsorption process. For the existing process, the initial condition for the problem can be written as:

$$
t=0 ; \quad T=T_{\mathrm{d}} ; \quad \bar{W}=\bar{W}_{\mathrm{d}}
$$

The boundary conditions for the problem are;

$$
\begin{aligned}
& R=R_{\mathrm{i}} ; \quad \partial T / \partial R=0 \\
& R=R_{\mathrm{o}} ; \quad T=T_{\mathrm{a}}
\end{aligned}
$$

The value of water vapor pressure at the entire adsorbent bed is considered $2 \mathrm{kPa}$. Moreover, for the analyzed process, the values of $T_{\mathrm{a}}, T_{\mathrm{d}}, W_{\mathrm{a}}$, and $W_{\mathrm{d}}$ are $303 \mathrm{~K}, 353 \mathrm{~K}, 0.3416 \mathrm{~kg} / \mathrm{kg}$, $0.077 \mathrm{~kg} / \mathrm{kg}$, respectively. 


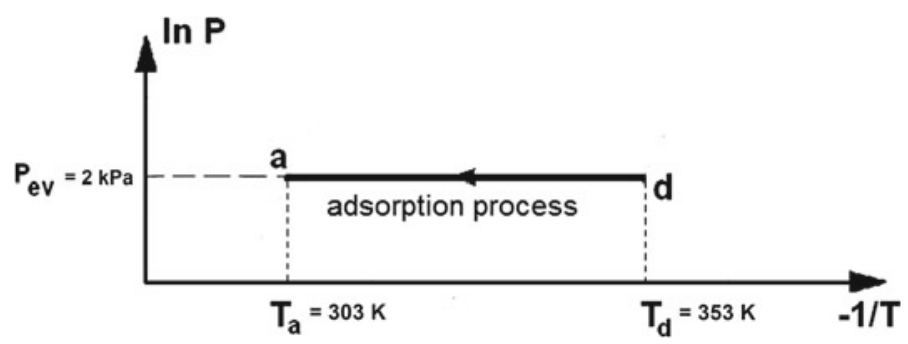

Fig. 3 A schematic view of the adsorption process on Clapeyron diagram

\subsection{Non-uniform Pressure Approach}

In this approach, the effect of interparticle mass transfer resistance is taken into account. The change of water vapor pressure in the voids between silica gel particles during the adsorption process is considered (Fig. 2b). The continuity equation based on conservation of mass for water vapor flowing in the voids between particles through the adsorbent bed can be written as (Nield and Bejan 2006):

$$
\varphi \frac{\partial \rho_{v}}{\partial t}+\frac{1}{R} \frac{\partial}{\partial R}\left(R \rho_{v} V_{\mathrm{r}}\right)+(\varphi-1) \rho_{\mathrm{s}} \frac{\partial \bar{W}}{\partial t}=0
$$

The heat transfer equation for the adsorbent bed involving the silica gel particle, water vapor, and adsorbed water can be written as (Nield and Bejan 2006):

$$
\left(\rho C_{\mathrm{p}}\right)_{\mathrm{eff}} \frac{\partial T}{\partial t}+\frac{1}{R} \frac{\partial}{\partial R}\left(R \rho_{v} V_{\mathrm{r}} C_{\mathrm{p}_{v}} T\right)=\lambda_{\text {eff }} \frac{1}{R} \frac{\partial}{\partial R}\left(R \frac{\partial T}{\partial R}\right)+(1-\varphi) \rho_{\mathrm{s}} \Delta H_{\mathrm{ads}} \frac{\partial \bar{W}}{\partial t}
$$

In the above equation, $V_{\mathrm{r}}$ is facial water vapor velocity and it can be calculated using Darcy Law. Darcy's law is a simple proportional relationship among the fluid flow rate through a porous medium, the fluid viscosity and the pressure drop for a given distance. For the present problem, it can be written as:

$$
V_{\mathrm{r}}=\frac{K_{\mathrm{app}}}{\mu}\left(-\frac{\partial P}{\partial r}\right)
$$

where $K_{\text {app }}$ and $\mu$ are apparent the permeability of the silica gel bed and the water vapor viscosity, respectively. The ideal gas relation is used to calculate the pressure change of the water vapor in the silica gel bed. For the water vapor, compressibility factors at 303 and 353 $\mathrm{K}$ and at pressure of $2 \mathrm{kPa}$ are found around one which means that ideal gas relation can be applied for the water vapor (Cengel and Boles 2006) in the bed.

The apparent permeability of the silica gel bed, $K_{\text {app }}$, can be calculated by the following relation (Leong and Liu 2004a):

$$
K_{\text {app }}=K_{\text {inh }}+\frac{\varphi \mu}{\tau P} D_{\text {bed }}
$$

where $K_{\text {inh }}$ is the inherent permeability and $D_{\text {bed }}$ is the mass diffusivity of the bed. The inherent permeability can be obtained using Blake-Kozeny relation which is valid for the void fractions less than 0.5 (Bird et al. 2002):

$$
K_{\text {inh }}=\frac{r_{\mathrm{p}}^{2} \varphi^{3}}{37.5(1-\varphi)^{2}}
$$


The water vapor can also be diffused in the voids between silica gel particles. Two diffusion mechanisms which are Knudsen and molecular diffusions should be taken into account. As known, when the collisions between a molecule and the pore walls occur more frequently than collisions between diffusing molecules, the diffusion is called as Knudsen diffusion, and it can be calculated from the following equation:

$$
D_{\mathrm{k}}=97 r_{\mathrm{p}} \sqrt{T / M}
$$

When the pore diameter is larger than the average distance between molecular collisions and the collisions between diffusing molecules occur more frequently than collisions between molecules and the pore wall, the diffusion mechanism is called as molecular diffusion. The molecular diffusivity can be obtained from:

$$
D_{\mathrm{m}}=0.02628 \frac{\sqrt{T^{3} / M}}{P \sigma^{2} \Omega}
$$

The effect of overall diffusion in the voids between the particles in the adsorbent bed can be obtained by considering both the effects of Knudsen and molecular diffusion (Bird et al. 2002):

$$
\frac{1}{D_{\text {bed }}}=\frac{1}{D_{\mathrm{m}}}+\frac{1}{D_{\mathrm{k}}}
$$

For the non-uniform pressure approach, the LDF relation (Eq. (2)) is also used to determine the change of mean water concentration in the silica gel particle at the given temperature and pressure. The initial and boundary conditions for the equations of non-uniform pressure approach are tabulated and given in Table 3. The initial temperature and water concentration in the silica gel is identical with the initial condition of uniform pressure approach. The bed outer surface is maintained at $T=T_{\mathrm{a}}=303 \mathrm{~K}$. The initial water vapor density is found using ideal gas relation considering $P=2 \mathrm{kPa}$ and $T_{\mathrm{d}}=353 \mathrm{~K}$. Water vapor enters from inner surface $\left(R=R_{\mathrm{i}}\right.$ ) into the bed at $2 \mathrm{kPa}$ and a thermal equilibrium condition exists between water vapor and silica gel at the entire bed. Since the velocity at the outer surface of the bed is zero (non-slip boundary condition), no pressure gradient of water vapor exists at the outer surface $\left(R=R_{\mathrm{O}}\right)$.

\section{Solution Method}

Finite difference method is used to solve the governing equations of both approaches. For the uniform pressure approach, the heat transfer equation is solved to determine the local temperature in the adsorbent bed. Then, the obtained temperature values are used to solve the mass transfer equation of the silica gel particles and to calculate the water concentration in the silica gel particle. An inner iteration is used to obtain the simultaneous solution of the mass transfer equation for the silica gel particle (Eq. (2)) and heat transfer equation for the adsorbent bed (Eq. (1)). After obtaining the simultaneous solution for a time step, the procedure continues for the next time step.

For non-uniform pressure approach, first mass transfer equation for silica gel particle (Eq. (2)), energy equation for the adsorbent bed (Eq. (12)) and continuity equation for the water vapor (Eq. (11)) are solved to find the water concentration in the silica gel particle and distribution of temperature and water vapor density in the bed. Then, the pressure distribution of water vapor is obtained using the temperature and adsorptive density distributions based on ideal gas relation. Finally, the water vapor velocity is obtained using Darcy Law 
Table 3 The initial and boundary conditions of the considered problem for the uniform and non-uniform pressure approach

\begin{tabular}{|c|c|c|c|}
\hline Dependent variable & B.C at $R=R_{\mathrm{i}}$ & B.C at $R=R_{\mathrm{O}}$ & Initial conditions \\
\hline \multicolumn{4}{|l|}{ Uniform pressure approach } \\
\hline Temperature (K) & $\partial T / \partial R=0$ & $T=303$ & $T=353$ \\
\hline Adsorptive pressure $(\mathrm{kPa})$ & $P=2$ & $P=2$ & $P=2$ \\
\hline Amount of adsorbate $\left(k g_{v} \mathrm{~kg}_{\mathrm{s}}^{-1}\right)$ & $W=f(P, T)$ & $W=f(P, T)$ & $\begin{array}{l}W=\text { initial value } \\
\text { @ } 353 \mathrm{~K}\end{array}$ \\
\hline Dimensionless temperature & $\partial \theta / \partial R^{*}=0$ & $\theta=0$ & $\theta=1$ \\
\hline Dimensionless adsorptive pressure & $P^{*}=0$ & $P^{*}=0$ & $P^{*}=0$ \\
\hline Dimensionless amount of adsorbate & $W^{*}=f\left(P^{*}, \theta\right)$ & $W^{*}=f\left(P^{*}, \theta\right)$ & $W^{*}=0$ \\
\hline \multicolumn{4}{|l|}{ Non-uniform pressure approach } \\
\hline Temperature $(\mathrm{K})$ & $\partial T / \partial R=0$ & $T=303$ & $T=353$ \\
\hline Adsorptive pressure $(\mathrm{kPa})$ & $P=2$ & $\partial P / \partial R=0$ & $P=f(\rho, T)$ \\
\hline Adsorptive density $\left(\mathrm{kg} \mathrm{m}^{3}\right)$ & $\rho_{v}=f(P, T)$ & $\rho_{v}=f(P, T)$ & $\begin{array}{l}\rho_{v}=\text { initial value } \\
\text { @ } 353 \mathrm{~K}\end{array}$ \\
\hline Amount of adsorbate $\left(\mathrm{kg}_{v} \mathrm{~kg}_{\mathrm{s}}^{-1}\right)$ & $W=f(P, T)$ & $W=f(P, T)$ & $\begin{array}{l}W=\text { initial value } \\
\text { @ } 353 \mathrm{~K}\end{array}$ \\
\hline Adsorptive velocity $\left(\mathrm{m} \mathrm{s}^{-1}\right)$ & $V_{\mathrm{r}}=f\left(\rho_{v}, K_{a p p}\right)$ & $V_{\mathrm{r}}=0$ & $V_{\mathrm{r}}=0$ \\
\hline Dimensionless temperature & $\partial \theta / \partial R^{*}=0$ & $\theta=0$ & $\theta=1$ \\
\hline Dimensionless adsorptive pressure & $P^{*}=0$ & $\partial P^{*} / \partial R^{*}=0$ & $P^{*}=f\left(\rho^{*}, \theta\right)$ \\
\hline Dimensionless adsorptive density & $\rho_{v}^{*}=f\left(P^{*}, \theta\right)$ & $\rho_{v}^{*}=f\left(P^{*}, \theta\right)$ & $\rho_{v}^{*}=0$ \\
\hline Dimensionless amount of adsorbate & $W^{*}=f\left(P^{*}, \theta\right)$ & $W^{*}=f\left(P^{*}, \theta\right)$ & $W^{*}=0$ \\
\hline Dimensionless adsorptive velocity & $V_{\mathrm{r}}^{*}=f\left(\rho_{v}^{*}, K_{\mathrm{app}}^{*}\right)$ & $V_{\mathrm{r}}^{*}=0$ & $V_{\mathrm{r}}^{*}=0$ \\
\hline
\end{tabular}

(Eq. (13)). Similar to the solution method employed in the uniform pressure approach, an inner iteration is used to obtain the simultaneous solution for temperature, water concentration in the silica gel particle, water vapor density, and water vapor velocity in the bed. After obtaining a simultaneous solution for a time step, the procedure continues for the next step. The following convergence criterion is used for the inner iterations in both approaches;

$$
\left|\frac{\phi^{n+1}-\phi^{n}}{\Delta \tau}\right|<10^{-5}
$$

where $\phi$ represents $\bar{W}$ and $T$. The outer loop procedure is terminated when the adsorbate concentration and temperature reach the final values of $\bar{W}=0.995 \bar{W}_{\mathrm{a}}$ and $T=0.005 T_{\mathrm{a}}$. The following equation is used to determine the average value of a dependent variable in the bed.

$$
\bar{\gamma}(t)=\frac{\int_{R_{\mathrm{i}}}^{R_{\mathrm{o}}} 2 R \gamma(R, t) \mathrm{d} R}{\left(R_{\mathrm{o}}^{2}-R_{\mathrm{i}}^{2}\right)}
$$

where $\gamma$ can be $T, P, \rho_{v}$ and $\bar{W}$. To save the computational time, the number of nodes inside the bed was taken as seven and it was sufficient to obtain accurate results. Figure 4 shows the variation of average bed temperature versus time for three different numbers of nodes of 5, 7, and 20, when the bed thickness is $10 \mathrm{~mm}$. As seen, the variations of the average bed temperature with time for three different node numbers are close to each other. Our 


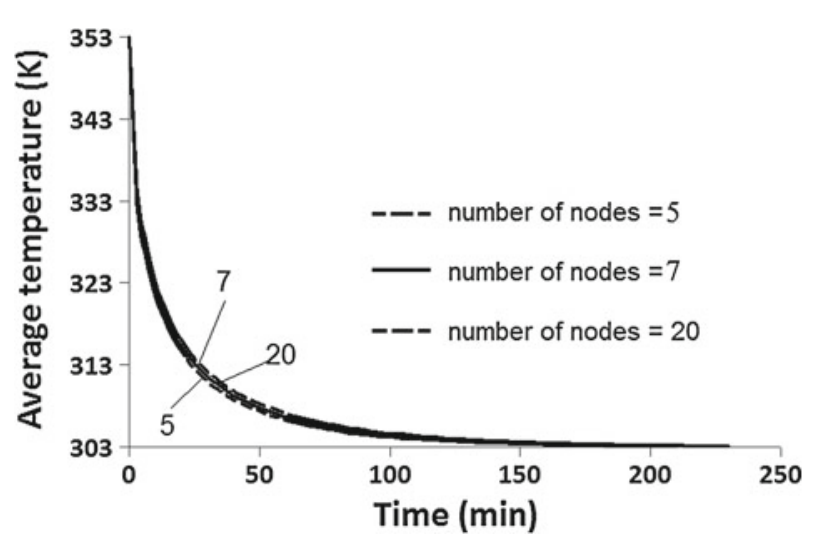

Fig. 4 The variation of average dimensionless temperature versus dimensionless time for three different number of nodes for the bed with $\Delta R=10 \mathrm{~mm}$

numerical observation showed that the relative difference between average temperature of solutions with 7 and 20 nodes is maximum $1 \%$.

\section{Results and Discussion}

As it was mentioned before, the results are obtained for silica gel-water pair. For all presented results, the adsorption process is started at $353 \mathrm{~K}$ and ended at $303 \mathrm{~K}$. For the uniform pressure approach, the water vapor pressure is assumed uniform as $2 \mathrm{kPa}$ in the entire bed during the adsorption process. For the non-uniform pressure approach, the water vapor pressure inside the adsorbent bed is not uniform and it varies. However, the water vapor pressure at the entrance of bed $\left(R=R_{\mathrm{i}}\right)$ is at $2 \mathrm{kPa}$.

Figure 5 shows the obtained numerical results of both uniform and non-uniform pressure approaches for an adsorbent bed with thickness of $40 \mathrm{~mm}$ and silica gel particle radius of 1 $\mathrm{mm}$. Figure 5a represents the change in average water concentration and temperature with time for both approaches. As seen, the average bed temperature decreases while the average of water concentration increases with time. The changes in $\bar{T}$ and $\bar{W}$ versus time for both approaches are very close to each other. The temperature change at $R=16.7$ and $43.3 \mathrm{~mm}$ locations for both approaches are illustrated in Fig. 5b. The local variations of temperature with time for both approaches are also close to each other. The temperature at both locations ( $R=16.7$ and $43.3 \mathrm{~mm}$ ) decreases from 353 to $303 \mathrm{~K}$. The temperature at $R=43.3 \mathrm{~mm}$ decreases faster than the temperature at $R=16.7 \mathrm{~mm}$ since the bed is cooled from the outer surface. The change of local adsorbate concentration with time at the same points throughout the adsorption process is illustrated in Fig. 5c. As expected, the local adsorbate concentration at $R=43.3 \mathrm{~mm}$ increases faster compared to the local concentration of $R=16.7 \mathrm{~mm}$ since the bed is cooled from the outer surface. Figure $5 \mathrm{~d}$ shows the change of pressure in the bed at the same locations for both approaches. The pressure at the entire bed does not vary with time and it is $2 \mathrm{kPa}$. The local pressure calculated by non-uniform pressure approach does not change with time and space, since the interparticle mass transfer resistance is negligible when $r_{\mathrm{p}}=1 \mathrm{~mm}$. Hence, the uniform pressure approach, which is simpler than non-uniform approach, can be used to simulate the adsorption process in this bed. 

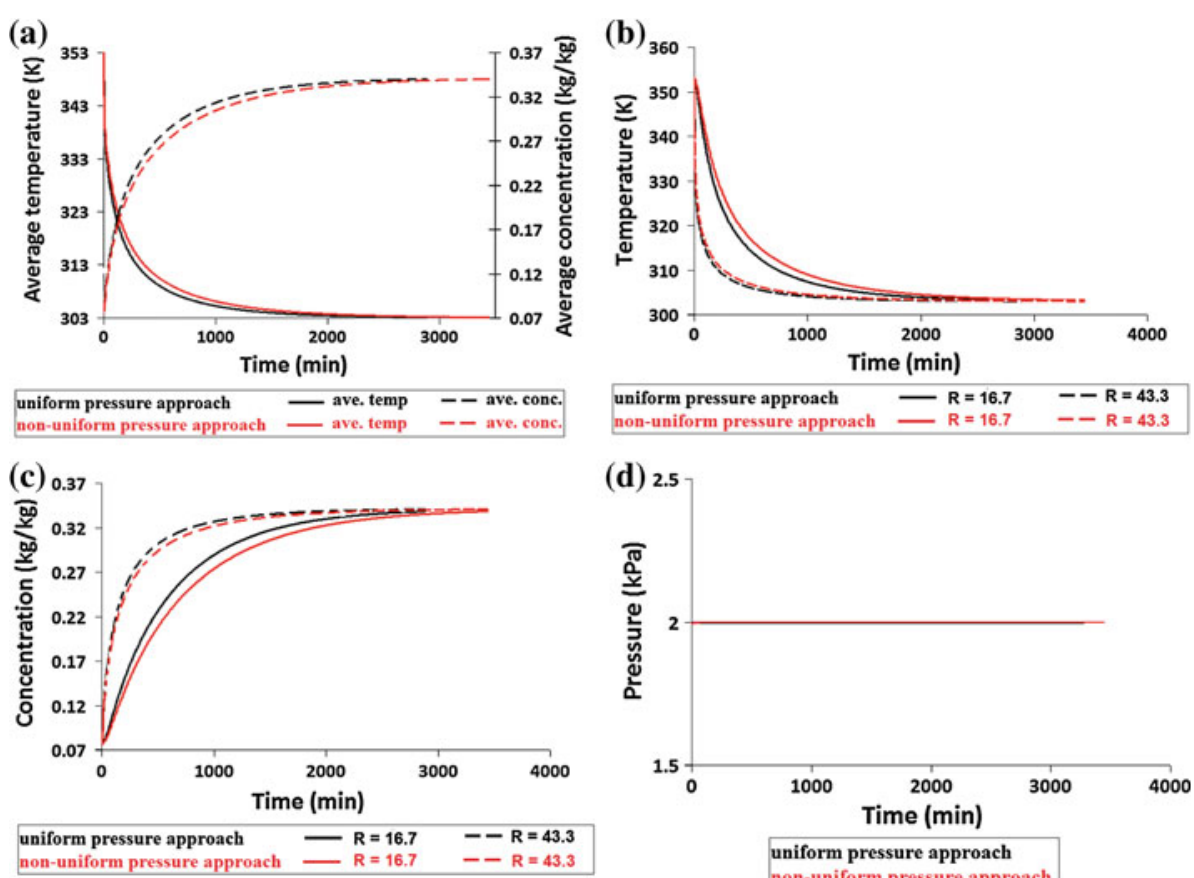

uniform pressure approach

non-uniform pressure approach

Fig. 5 The numerical results of both uniform and non-uniform pressure approaches for an adsorbent bed with $R_{\mathrm{i}}=10 \mathrm{~mm}, R_{\mathrm{O}}=50 \mathrm{~mm}, r_{\mathrm{p}}=1 \mathrm{~mm}$, a average adsorbate concentration and temperature, $\mathbf{b}$ the local adsorbate temperature at $R=16.7$ and $43.3 \mathrm{~mm}$, c the local adsorbate concentration at $R=16.7$ and 43.3 $\mathrm{mm}, \mathbf{d}$ the local pressure at $R=16.7$ and $43.3 \mathrm{~mm}$

Figure 6 presents the results of the same bed discussed in Fig. 5, but for the silica gel particle radius of $r_{\mathrm{p}}=0.025 \mathrm{~mm}$. By comparison of Figs. 5 and 6, it can be seen that the decrease of silica gel particle radius from 1 to $0.025 \mathrm{~mm}$ extends the adsorption process period. The reducing particle size increases the effect of interparticle mass transfer resistance and consequently the water vapor flows slower in the voids between particles. As can be seen from Fig. 6a, the uptake curves of the uniform and non-uniform pressure approaches are split from each other. If the uniform pressure approach is used to simulate the problem, the obtained period of adsorption become considerably shorter than the non-uniform pressure approach. The total adsorption time of the non-uniform pressure approach is longer than that of uniform pressure approach since the effect of interparticle mass transfer resistance is involved. The comparison of two approaches indicates that the invalidity of the uniform pressure approach for the considered bed with adsorbent particle radius of $0.025 \mathrm{~mm}$. Figure $6 \mathrm{~b}, \mathrm{c}$ show the variation of temperature and adsorbate concentration in the bed at $R=16.7$ and $43.3 \mathrm{~mm}$ locations. Both the variations of temperature and adsorbate concentration of uniform and non-uniform pressure approaches in these locations are different. The difference between the concentration variations of two approaches versus time is expected due to the significant of interparticle mass transfer resistance. Figure $6 \mathrm{~d}$ indicates the variations of water vapor pressure at $R=16.7$ and $43.3 \mathrm{~mm}$ locations during adsorption process for both approaches. For uniform pressure approach, the pressure does not change at both locations throughout the adsorption process, as expected. However, for the non-uniform pressure approach, the pressure at $R=43.3 \mathrm{~mm}$ drops from 2 to $0.4 \mathrm{kPa}$ at the beginning of the adsorption process 

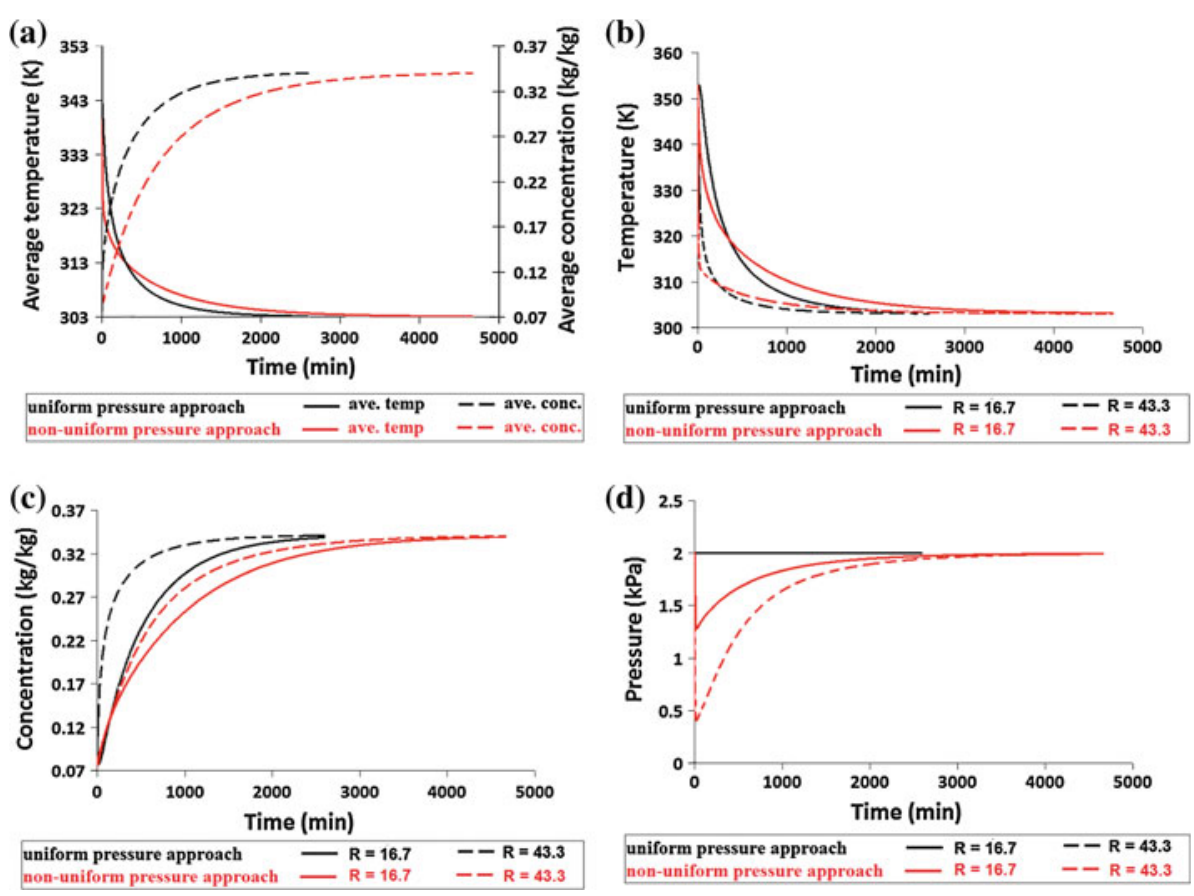

Fig. 6 The numerical results of both uniform and non-uniform pressure approaches for an adsorbent bed with $R_{\mathrm{i}}=10 \mathrm{~mm}, R_{\mathrm{O}}=50 \mathrm{~mm}, r_{\mathrm{p}}=0.025 \mathrm{~mm}$, a average adsorbate concentration and temperature, $\mathbf{b}$ the local adsorbate temperature at $R=16.7$ and $43.3 \mathrm{~mm}$, $\mathbf{c}$ the local adsorbate concentration at $R=16.7$ and 43.3 $\mathrm{mm}$, d the local pressure at $R=16.7$ and $43.3 \mathrm{~mm}$

and then it slowly increases to $2 \mathrm{kPa}$. By decreasing temperature in the outer region of adsorbent bed, water vapor in this region is adsorbed by silica gel particles. The decrease of pressure in this region can be observed since water vapor does not easily flow from the inner to outer region due to interparticle mass transfer. Similar a pressure change is seen for the location of $R=16.7 \mathrm{~mm}$. The rate of pressure drop at the beginning of adsorption process at $R=16.7 \mathrm{~mm}$ location is less than that of $R=43.3 \mathrm{~mm}$, since it is closer to the water vapor inlet and the local temperature decreases slowly.

In order to understand the effect of adsorbent bed thickness on the interparticle mass transfer resistance, Figs. 7 and 8 are presented. Figures 7 and 8 depict the changes of temperature and adsorbate concentration for the bed with thickness of $10 \mathrm{~mm}$ filled with silica gel particle radius of $r_{\mathrm{p}}=1$ and $0.025 \mathrm{~mm}$, respectively. As can be seen from Fig. 7, for the adsorbent bed with $r_{\mathrm{p}}=1 \mathrm{~mm}$, the results of both uniform and non-uniform pressure approaches overlap each other, not only for the average bed temperature and concentration but also for local temperature, adsorbate concentration and pressure at $R=11.7$ and 18.3 $\mathrm{mm}$. This indicates that the validity of uniform pressure approach for the bed with silica gel particle size of $r_{\mathrm{p}}=1 \mathrm{~mm}$. The comparison of Figs. 5 and 7 shows that the reducing bed thickness from 40 to $10 \mathrm{~mm}$ decreases adsorption period from 3,440 to $588 \mathrm{~min}$. Although, the water vapor can easily move in the voids between adsorbent particles for the bed with the particles of $r_{\mathrm{p}}=1 \mathrm{~mm}$, the decrease of bed thickness reduces bed thermal resistance in radial direction which results in the decrease of adsorption period. The decrease of adsorbent particle from 1 to $0.025 \mathrm{~mm}$ causes splitting of the curves due to the enhancement of the 

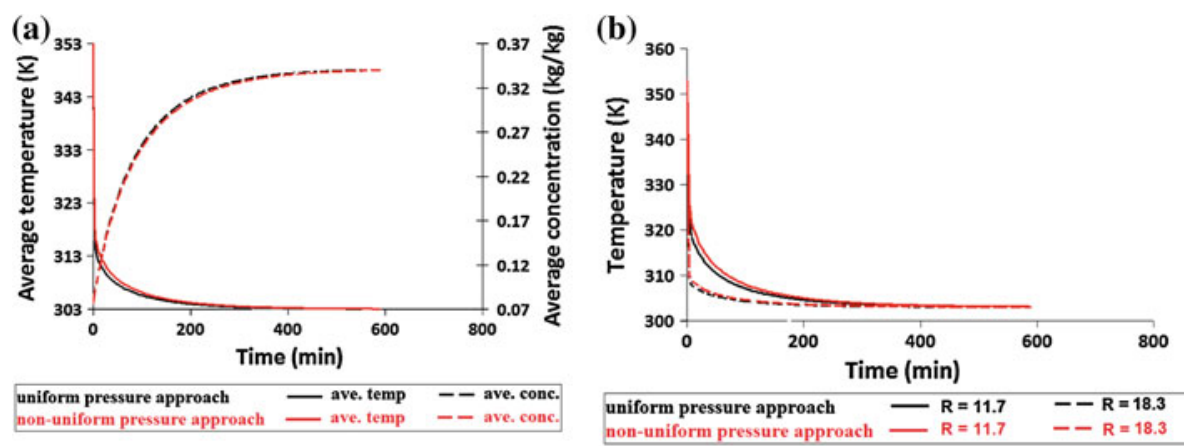

(c)
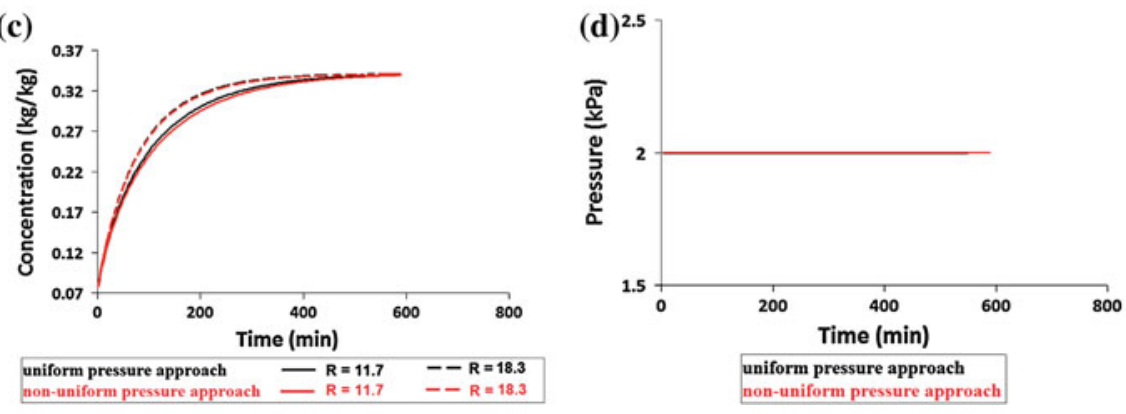

Fig. 7 The numerical results of both uniform and non-uniform pressure approaches for an adsorbent bed with $R_{\mathrm{i}}=10 \mathrm{~mm}, R_{\mathrm{O}}=20 \mathrm{~mm}, r_{\mathrm{p}}=1 \mathrm{~mm}$, a average adsorbate concentration and temperature, $\mathbf{b}$ the local adsorbate temperature at $R=11.7$ and $18.3 \mathrm{~mm}$, $\mathbf{c}$ the local adsorbate concentration at $R=11.7$ and 18.3 $\mathrm{mm}$, d the local pressure at $R=11.7$ and $18.3 \mathrm{~mm}$

interparticle mass transfer resistance as seen from Fig. 8. A pressure drop is observed at the outer region of the bed at the beginning of adsorption period due to the sudden decrease of temperature and slow transfer of water vapor in the radial direction of the bed (Fig. 8d). By reduction silica gel particle size, the interparticle mass transfer increases, hence the increase of adsorption period is expected. However, the comparison of the Figs. 7 and 8 shows that the adsorption period is decreased by reducing silica gel particle size. The reason of this reduction is explained later in this section.

Figure 9 shows the concentration and temperature profiles obtained by the uniform and non-uniform pressure approaches in the adsorbent bed at different time steps for $r_{\mathrm{P}}=1$ and $0.025 \mathrm{~mm}$ and adsorbent bed thickness of $10 \mathrm{~mm}$. The concentration and temperature profiles of two approaches at the time steps of 1,10 , and $100 \mathrm{~min}$ are very close to each other since the interparticle mass transfer resistance is negligible in the bed with for $r_{\mathrm{P}}=1$ $\mathrm{mm}$. By reducing particle size from 1 to $0.025 \mathrm{~mm}$, the interparticle mass transfer resistance of the bed increases and that is why the temperature and concentration profiles in the bed are split from each other. Particularly, there is a big difference between the concentration profiles obtained by uniform and non-uniform pressure approaches for $r_{\mathrm{P}}=1 \mathrm{~mm}$ (Fig. 9d). The concentration of particles at the outer region becomes to final equilibrium value since their size is very small $\left(r_{\mathrm{P}}=0.025 \mathrm{~mm}\right)$. This figure shows the huge difference between the results of uniform and non-uniform approaches if the interparticle mass transfer resistance is neglected for a bed with small particle size.

Figure 10 compares the changes in average temperature and adsorbate concentration of the bed with $10 \mathrm{~mm}$ thickness for three different silica gel particle radii of $0.7,0.1$, and 

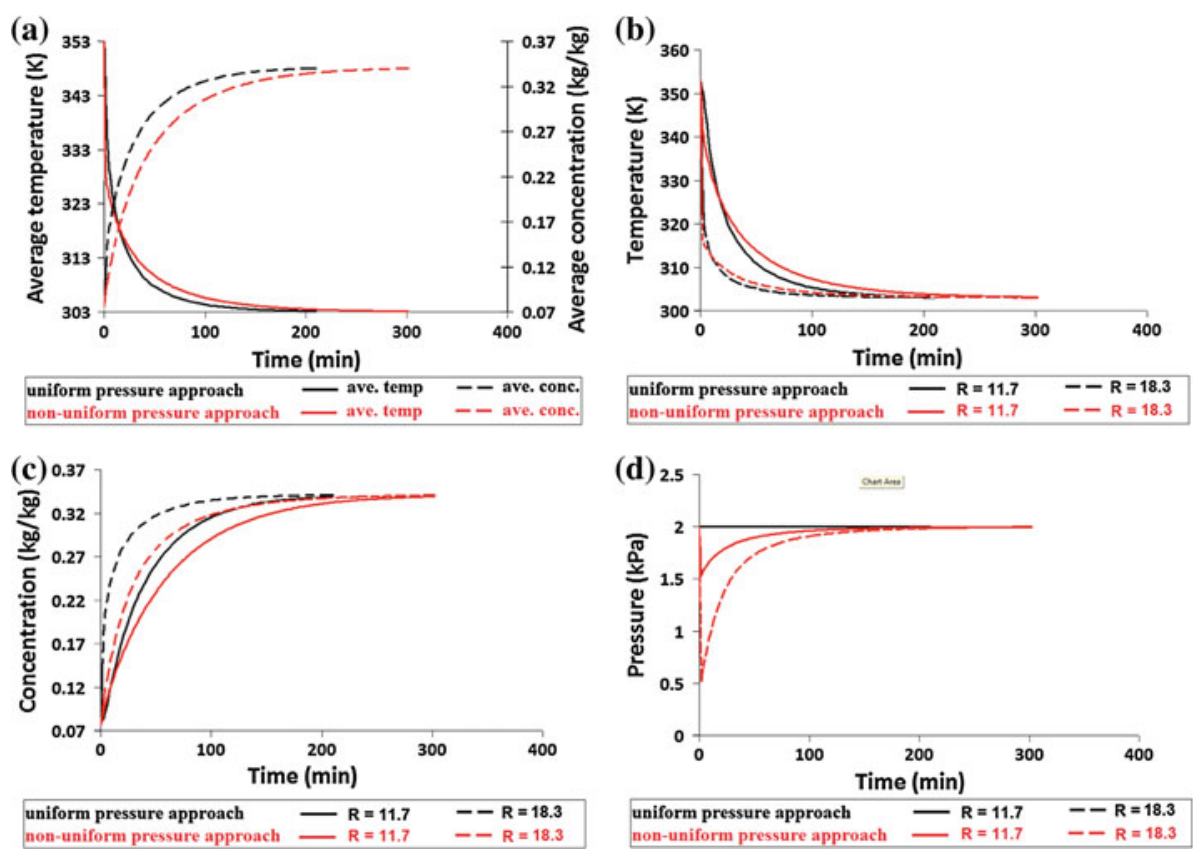

Fig. 8 The numerical results of both uniform and non-uniform pressure approaches for an adsorbent bed with $R_{\mathrm{i}}=10 \mathrm{~mm}, R_{\mathrm{O}}=20 \mathrm{~mm}, r_{\mathrm{p}}=0.025 \mathrm{~mm}$, a average adsorbate concentration and temperature, $\mathbf{b}$ the local adsorbate temperature at $R=11.7$ and $18.3 \mathrm{~mm}$, c the local adsorbate concentration at $R=11.7$ and 18.3 $\mathrm{mm}$, d the local pressure at $R=11.7$ and $18.3 \mathrm{~mm}$

$0.0075 \mathrm{~mm}$. The non-uniform pressure approach is used to obtain these results. The adsorbate concentration increases from 0.077 to $0.3416 \mathrm{~kg} / \mathrm{kg}$ while the temperature decreases from 353 to $303 \mathrm{~K}$. The adsorption period decreases from 408 to $257 \mathrm{~min}$ by reducing particle size from $r_{\mathrm{P}}=0.7$ to $0.1 \mathrm{~mm}$ due to the reduction in intraparticle mass transfer resistance. However, further reduction of particle size from 0.1 to $0.0075 \mathrm{~mm}$ increases adsorption period from 257 to $497 \mathrm{~min}$ due to the increase of interparticle mass transfer resistance. The reduction of particle size makes voids between particles smaller and enhances flow resistance through the bed. The result of this figure clearly shows that the neglecting interparticle mass transfer resistance in a granular bed with $r_{\mathrm{P}}<0.1 \mathrm{~mm}$ causes a significant mistake in the results.

The comments on Fig. 10 can be improved by Fig. 11 in which the total adsorption period versus adsorbent particle radius is plotted for the bed thickness of 40 and $10 \mathrm{~mm}$. The adsorption period is defined when the average adsorbate concentration in the bed is reached $90 \%$ of final value (i.e., $\bar{W}_{\mathrm{a}}=0.3416 \mathrm{~kg} / \mathrm{kg}$ ). For the bed with thickness of 10 and $40 \mathrm{~mm}$, the adsorption periods for $r_{\mathrm{P}}=1 \mathrm{~mm}$ are 205 and 1,065 min, respectively. For both bed thickness, the adsorption period decreases by reducing the adsorbent particle size. This trend continues up to a specific particle size. After it, the adsorption period increases with decrease of silica gel particle size. For instance, for the adsorbent bed with thicknesses of $10 \mathrm{~mm}$, the adsorption period decreases from 205 to $82 \mathrm{~min}$ by reducing silica gel particle size from 1.0 to $0.1 \mathrm{~mm}$. In this region of the particle size, the intraparticle mass transfer resistance is dominant and interparticle mass transfer resistance can be neglected. Hence, the reduction of the particle size reduces intraparticle mass transfer resistance and consequently the adsorption period decreases. The decrease of silica gel particle radius from 0.1 to 0.0075 

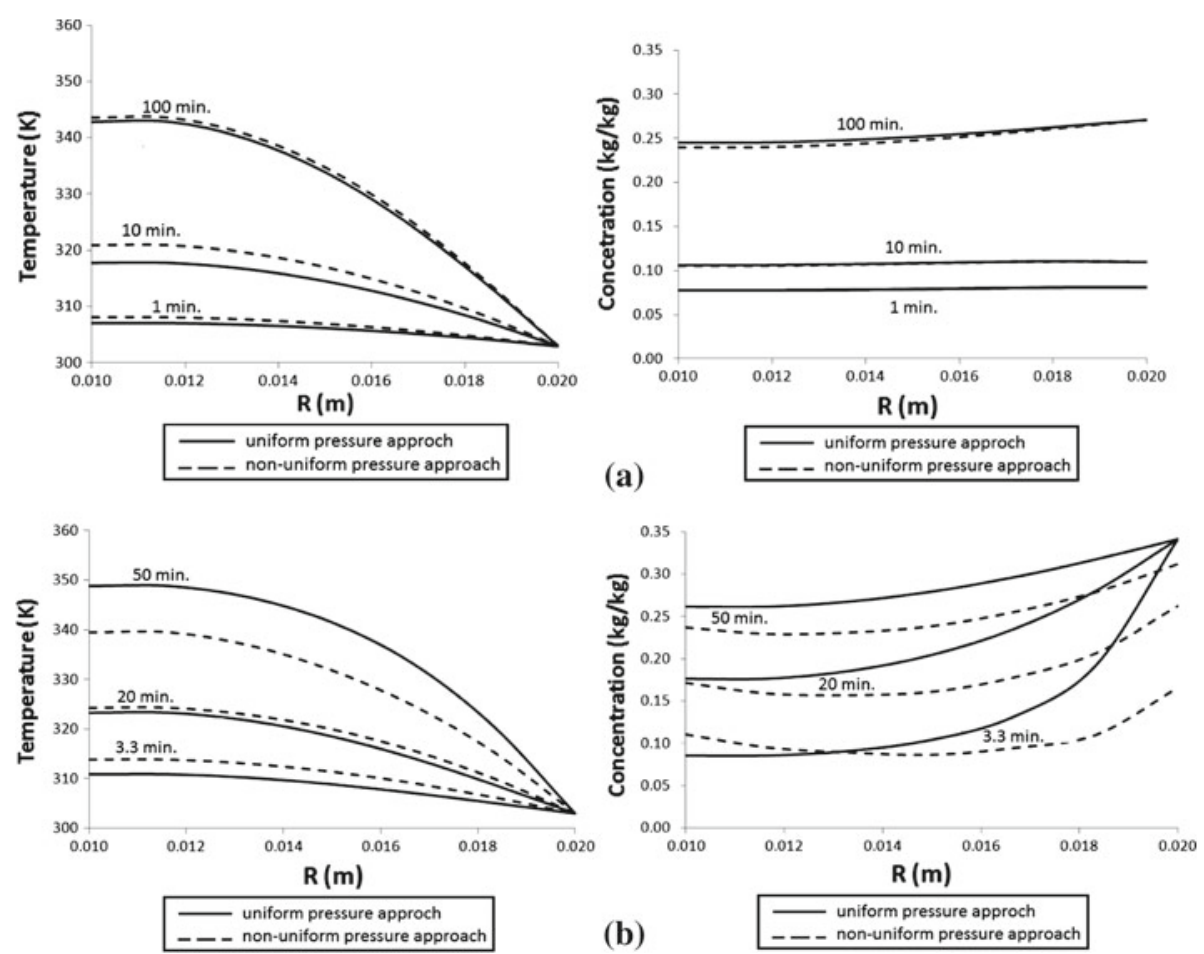

Fig. 9 Temperature and concentration profiles obtained by uniform and non-uniform pressure approaches for a bed with $R_{\mathrm{i}}=10 \mathrm{~mm}, R_{\mathrm{O}}=20 \mathrm{~mm} \mathbf{a} r_{\mathrm{P}}=1 \mathrm{~mm}, \mathbf{b} r_{\mathrm{p}}=0.025 \mathrm{~mm}$

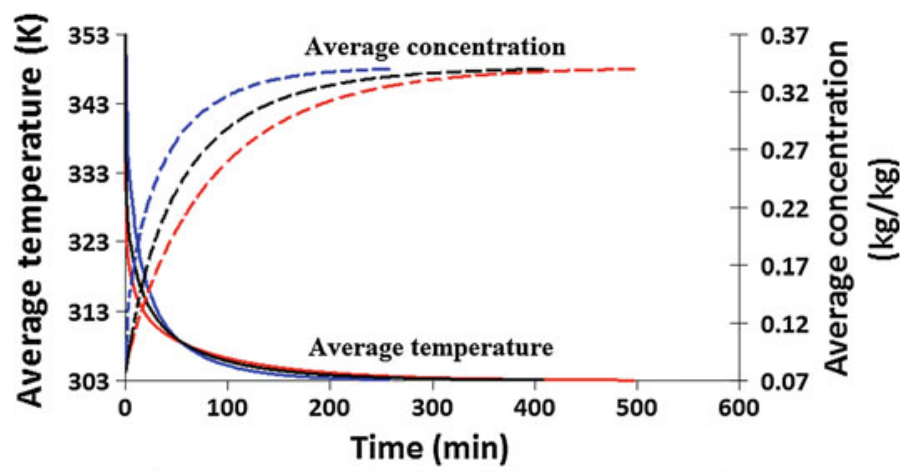

\section{$-\mathrm{rp}=0.0075 \mathrm{~mm}-\mathrm{rp}=0.1 \mathrm{~mm}-\mathrm{rp}=0.7 \mathrm{~mm}$}

Fig. 10 The comparison of the average adsorbate concentration and temperature for the bed with $10 \mathrm{~mm}$ thickness and different adsorbent particle size

$\mathrm{mm}$ increases the adsorption period from 82 to $185 \mathrm{~min}$, since the interparticle mass transfer resistance becomes significant. Figure 11 shows that there should be an optimum adsorbent particle size that provides minimum adsorption period for a granular adsorbent bed. For the adsorbent bed with $10 \mathrm{~mm}$ thickness, the adsorbent particle with $r_{\mathrm{P}}=0.1 \mathrm{~mm}$ provides the 
Fig. 11 The change of adsorption period with adsorbent particle size for the bed thickness of 10 and $40 \mathrm{~mm}$

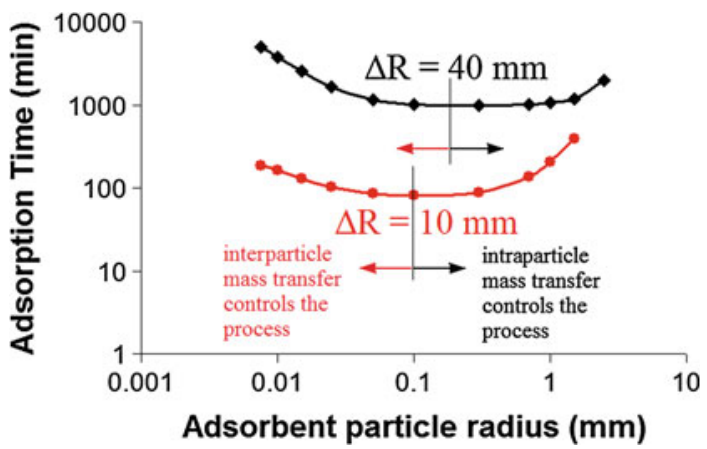

shortest adsorption period while for the bed with $40 \mathrm{~mm}$ thickness the minimum adsorption period can be achieved using adsorbent particle size of $0.3 \mathrm{~mm}$.

\section{Conclusion}

The heat and mass flow in a granular type adsorbent bed for a non-isothermal adsorption process are analyzed by uniform and non-uniform pressure approaches. The study is performed for silica gel-water pair. Based on the results obtained by two approaches, following remarks can be concluded:

- The uniform pressure approach can be used to simulate the heat and mass transfer in a granular adsorbent bed when the voids between particles are sufficiently large and the interparticle mass transfer is negligible (e.g., $r_{\mathrm{P}}=1 \mathrm{~mm}$ ). For the bed with small particle size, the results of uniform pressure approach may not be valid (e.g., $r_{\mathrm{P}}=0.025 \mathrm{~mm}$ ).

- A sudden pressure drop is observed at the outer region of adsorbent bed with small particle size (e.g., $r_{\mathrm{P}}=0.0075 \mathrm{~mm}$ ). This change in local pressure cannot be observed if the uniform pressure approach is used.

- The interparticle mass transfer resistance is enhanced by the decrease of particle size. After a specified adsorbent particle size, the interparticle mass transfer resistance becomes dominant and it increases the adsorption period. There is a size of adsorbent particle behind that, the interparticle mass transfer resistance controls adsorption period.

- There is an optimum adsorbent particle size for which the minimum adsorption period is achieved. The optimum particle size varies with the adsorbent bed thickness. For the considered bed thickness of $R=10 \mathrm{~mm}$ and $40 \mathrm{~mm}$, the optimum particle size are found around 0.1 and $0.3 \mathrm{~mm}$, respectively.

- The adsorption period is highly affected by bed thickness. The increase of bed thickness enhances thermal resistance along the bed and consequently adsorption period increases. The increase of bed thickness from 10 to $4 \mathrm{~mm}$ when particle radius is $1 \mathrm{~mm}$ (no interparticle mass transfer resistance) enhances adsorption period by $419 \%$.

The present study is performed to show the effect of interparticle mass transfer resistance on the determination of adsorption period in an adsorbent bed. Further study should be performed on different adsorbent-adsorbate pair to observe the effect of interparticle mass transfer on the mass transfer mechanism in the bed and to develop a relation between the adsorption period with the adsorbent particle size and adsorbent bed thickness for various adsorbent-adsorbate pairs. 
Acknowledgements The authors express their very sincere thanks to the reviewers for their valuable comments and suggestions.

\section{References}

Al-Sharqawi, H.S., Lior, N.: Conjugate computation of transient flow and heat and mass transfer between humid air and desiccant plates and channels. Numer. Heat Transf. A 46, 525-548 (2004)

Amar, N.B., Sun, L.M., Meunier, F.: Numerical analysis of adsorptive temperature wave regenerative heat pump. Appl. Therm. Eng. 16, 405-418 (1996)

Bird, B.R., Stewart, E.W., Lightfoot, N.E.: Transport Phenomena, 2nd edn, pp. 189-191. Wiley, New York (2002)

Chahbani, H.M., Labidi, J., Paris, J.: Effect of mass transfer kinetics on the performance of adsorptive heat pump systems. Appl. Therm. Eng. 22, 23-40 (2002)

Chahbani, H.M., Labidi, J., Paris, J.: Modeling of adsorption heat pumps with heat regeneration. Appl. Therm. Eng. 24, 431-447 (2004)

Cengel, Y.A., Boles, M.A.: Thermodynamics: An Engineering Approach. McGraw-Hill Higher Education, New York (2006)

Chua, H.T., Ng, K.C., Wang, W., Yap, C., Wang, X.L.: Transient modeling of a two-bed silica gel-water adsorption chiller. Int. J. Heat Mass Transf. 47, 659-669 (2004).

Close, D.J., Dunkle, R.V.: Use of adsorbent beds for energy storage in drying and heating systems. Sol. Eng. 19, 233 (1977)

Cussler, E.L.: Diffusion Mass Transfer in Fluid Systems, 2nd edn, pp. 104-109. Cambridge University Press, Cambridge (1997)

Demir, H., Mobedi, M., Ülkü, S.: A review on adsorption heat pump: problems and solutions. Renew. Sust. Eng. Rev. 12, 2381-2403 (2008)

Demir, H., Mobedi, M., Ülkü, S.: Effects of porosity on heat and mass transfer in a granular adsorbent bed. Int. Commun. Heat Mass Transf. 36, 372-377 (2009)

Golubovic, M.N., Worek, W.M.: Influence of elevated pressure on sorption in desiccant wheels. Numer. Heat Transf. A 45, 869-886 (2004)

Hajji, A., Lavan, Z.: Numerical solution of nonlinear hyperbolic equations governing a regenerative closedcycle adsorption cooling and heating system. Numer. Heat Transf. A 21, 1-19 (2007)

Ilis, G.G., Mobedi, M., Ülkü, S.: A parametric study on isobaric adsorption process in a closed adsorbent bed. Int. Commun. Heat Mass Transf. 37, 540-547 (2010)

Ilis, G.G., Mobedi, M., Ülkü, S.: A dimensionless analysis of heat and mass transport in an adsorber with thin fins; uniform pressure approach. Int. Commun. Heat Mass Transf. 38, 790-797 (2011)

Incropera, P.F., DeWitt, P.D.: Fundamentals of Heat and Mass Transfer, 4th edn. Wiley, New York (1996)

Karger, J., Ruthven, M.D.: Diffusion in Zeolites and Other Microporous Solids. Wiley, New York (1992)

Leong, K.C., Liu, Y.: Numerical study of a combined heat and mass recovery adsorption cooling cycle. Int. J. Heat Mass Transf. 47, 4761-4770 (2004a)

Leong, K.C., Liu, Y.: Numerical modeling of combined heat and mass transfer in the adsorbent bed of a zeolite/water cooling system. Appl. Therm. Eng. 24, 2359-2374 (2004b)

Leong, K.C., Liu, Y.: System performance of a combined heat and mass recovery adsorption cooling cycle: a parametric study. Int. J. Heat Mass Transf. 49, 2703-2711 (2006)

Leong, K.C., Liu, Y.: Numerical modeling of a zeolite/water adsorption cooling system with non-constant condensing pressure. Int. Commun. Heat Mass Transf. 35, 618-622 (2008)

Li, Y., Sumathy, K.: Comparison between heat transfer and heat mass transfer models for transportation process in an adsorbent bed. Int. Commun. Heat Mass Transf. 47, 1587-1598 (2004)

Liu, Y., Leong, K.C.: The effect of operating conditions on the performance of zeolite/water adsorption cooling systems. Appl. Therm. Eng. 22, 1403-1418 (2005)

Maggio, G., Gordeeva, L.G., Freni, A., Aristov, Y.I., Santori, G., Polonara, F., Restuccia, G.: Simulation of a solid sorption ice-maker based on the novel composite sorbent "lithium chloride in silica gel pores". Appl. Therm. Eng. 29, 1714-1720 (2009)

Marletta, L., Maggio, G., Freni, A., Ingrasciotta, M., Restuccia, G.: A non-uniform temperature non-uniform pressure dynamic model of heat and mass transfer in compact adsorbent beds. Int. J. Heat Mass Transf. 45, $3321-3330(2002)$

Nield, D.A., Bejan, A.: Convection in Porous Media. Springer, New York (2006)

Restruccia, G., Freni, A., Maggio, G.: A zeolite-coated bed for air conditioning adsorption systems: parametric study of heat and mass transfer by dynamic simulation. Appl. Therm. Eng. 6, 19-30 (2002) 
Restuccia, G., Freni, A., Vasta, S., Aristov, Y.: Selective water sorbent for solid sorption chiller: experimental results and modeling. Int. J. Refrig. 27, 284-293 (2004)

Ruivo, C.R., Costa, J.J., Figueiredo, A.R.: Analysis of simplifying assumptions for the numerical modeling of the heat and mass transfer in a porous desiccant medium. Numer. Heat Transf. A 49, 851-872 (2006)

Ruivo, C.R., Costa, J.J., Figueiredo, A.R.: Numerical study of the cyclic behavior of a desiccant layer of a hygroscopic rotor. Numer. Heat Transf. A 53, 1037-1053 (2008)

Saha, B.B., Chakraborty, A., Koyama, S., Aristov, Y.I.: A new generation cooling device employing $\mathrm{CaCl}_{2}$ in silica gel water system. Int. J. Heat Mass Transf. 52, 516-524 (2009)

Sakoda, A., Suzuki, M.: Fundamental study on solar powered adsorption cooling system. J. Chem. Eng. Japan. 17, 52-57 (1984)

Sakoda, A., Suzuki, M.: Simultaneous transport of heat and adsorbate in closed type adsorption cooling system utilizing solar heat. J. Sol. Eng. Eng. Trans. ASME 108, 239-245 (1986)

San, J., Lin, W.: Comparison among three adsorption pairs for using as the working substances in a multi-bed adsorption heat pump. Appl. Therm. Eng. 28, 988-997 (2008)

Sun, L.M., Amar, N.B., Meunier, F.: Numerical study on coupled heat and mass transfers in an adsorber with external fluid heating. Heat Recovery Syst. 15, 19-29 (1995)

Sphaier, L.A., Worek, W.M.: Numerical solution of periodic heat and mass transfer with adsorption in regenerators: analysis and optimization. Numer. Heat Transf. A 53, 1133-1155 (2008)

Tchernev, D.I.: Solar applications of natural zeolites. In: Proceedings of Natural Zeolites Occurrence Properties and Use, Oxford (1976)

Tchernev, D.I.: The use of zeolites for solar cooling. In: Proceedings of 5th Inter Conference on Zeolites, Naples, Italy (1980)

Wang, X., Chua, H.T.: A comparative evaluation of two different heat-recovery schemes as applied to a two-bed adsorption chiller. Int. J. Heat Mass Transf. 50, 433-443 (2007) 